\title{
PENGARUH KUALITAS PELAYANAN TERHADAP KEPUASAN WISATAWAN PADA ISTANA MAIMUN
}

\author{
Endang Silalahi, M. Abbas, Suprianto \\ Alumni Sekolah Tinggi Ilmu Manajemen Sukma \\ Program studi Manajemen, Sekolah Tinggi Ilmu Manajemen \\ abbashmad990@gmail.com, supriantosu80@gmail.com
}

\begin{abstract}
The study entitled the influence of service quality to the satisfaction of tourists in Maimoon Palace to determine whether the quality of the influence of quality of service to the satisfaction of tourists at Maimoon Palace. The population of this study are tourists who visit Maimoon Palace. Sampling method using random sampling counted 103 respondents. This research data is analyzed using Partial Test ( $\mathrm{t}$ test) and coefficient of determination $\left(\mathrm{R}^{2}\right.$ ) while data processing using SSPS 20. Where previously been through validity test and reability of research instrument. The results showed that based on the test partially indicated that the quality of service has a positive impact on the satisfaction of tourists at Maimoon Palace Medan. While the quality of service ability explain the level of tourist visit is $28,6 \%$ while the rest is explained by other variable which is explained which is not intended in this research model.

Keywords: Quality of Service, Tourist Satisfaction.
\end{abstract}

\section{PENDAHULUAN}

Pelayanan merupakan faktor yang sangat menentukan keberhasilan suatu perusahaan dan organisasi yang berorintasi pada profit. Pelayanan berkaitan dengan tingkat kepusaan pelanggan dimana pelanggan dapat merasakan kepuasan atas pelayanan yang diberikan akan menjadi pelanggan setia, meskipun banyak produk jasa lain yang sejenis begitu banyak dan mudah diperoleh. Untuk memenuhi kepuasan konsumen pada industri jasa, kualitas pelayanan sangat penting dikelola perusahaan objek wisata dengan baik.

Menurut penelitian yang dilakukan olehDetmuliati et al (2014) dalam judul skripsi penagaruh kualitas pelayanan tehadap kepuasan pengunjung di objek wisata FantasiLabersa Water \&Themepark menyatakan bahwa kualitas pelayanan terhadap kepuasan pengunjung secara simultan kualitas pelayanan sangat berpengaruh signifikan terhadapa kepuasan wisatawan. Pelayanan yang baik akan berdampak positif bagi wisatawan. Wisatawan akan merasa puas dan merasa dihargai sehingga akan tetap merasa senang untuk menjadi pelanggan yang setia pada suatu objek wisata yang dikunjungi. Menurut penelitian yang dilakukan oleh Rosita et al (2016) dalam judul skripsi pengaruh fasilitas wisata dan kualitas pelayanan terhadap kepuasan pengunjung di Taman Margasatwa Ragunan Jakarta. Bahwa seraca simultan pengaruh fasilitas wisata dan kualitas pelayanan berpengaruh positif terhadap kepuasan pengunjung. Kualitas pelayanan yang baik memiliki arti penting bagi kelangsungan hidup perusahaan karena dapat menciptakan kepuasan pelanggan. Perusahaan memperhatikan dan memberikan kebutuhan konsumen dengan memberikan pelayanan yang terbaik agar konsumen merasa puas dan dapat merekomendasikan kepada orang lain.

\section{Perumusan Masalah}

Berdasarkan uraian diatas, maka penulis merumusakan masalah penelitian ini sebagai berikut: "Apakah ada pengaruh kualitas pelayanan terhadap kepuasan wisatawan di Istana Maimoon?

\section{Batasan Masalah}

Untuk memperjelas arah penelitian ini dibatasi hanya membahas tentang pengaruh Kualitas pelayanan terhadap kepuasaan wisatawan domestik khususnya para pelajar dan mahasiswa yang berkunjung ke Istana Maimoon selama April-Mei 2017. 


\section{Tujuan Penelitian}

Adapun tujuan dari penelitian ini adalah untuk mengetahui pengaruh kualitas pelayanan terhadap kepuasan wisatawan di Istana Maimoon Medan.

\section{Manfaat Penelitian}

Mamfaat yang diambil dari penelitian ini adalah

1. Bagi peneliti

Untuk memenuhi salah satu syarat dalam menyelesaikan Program S1 di Sekolah Tinggi Ilmu Manajemen Sukma dan sebagai sarana dalam penerapan ilmu pengetahuan, menambah pengetahuan peneliti khususnya berkenaan dengan pengaruh kualitas pelayanan terhadap kepuasan wisatawan.

2. Bagi pengelola objek wisata,

Sebagai masukan dan sumbang saran bagi pihak manajemen Istana Maimoon sebuhungan dengan penelitian yang penulis lakukan di objek wisata tersebut.

3. Bagi Sekolah Tinggi Manajemen Sukma

4. Sebagai tambahan hasil penelitian yang dapat digunakan sebagai bahan rujukan dan dikembangkan lebih lanjut.

5. Bagi peneliti selanjutnya

Sebagai bahan referensi khususnya mengenai masalah kualitas pelayanan di objek wisata.

\section{METODE PENELITIAN}

\section{Jenis dan Sumber Data}

Data yang digunakan dalam penelitian ini adalah data primer dan data sekunder.

1. Data primer adalah sumber data yang secara langsung memberikan data kepada pengumpul data (Sugiyono, 2012:25). Data primer berupa catatan

hasil wawancara yang diperoleh melalui wawancara yang penulis lakukan. selain itu mengumpulkan data dalam bentuk catatan tentang situasi dan kejadian di perpustakaan

2. Data sekunder merupakan sumber data yang tidak memberikan informasi secara langsung kepada pengumpul data. Data sekunder ini dapat berupa hasil pengolahan lebih lanjut dari data primer yang disajikan dalam bentuk lain atau orang lain (Sugiono, 2012:25) data ini digunakan untuk mendukung informasi dari data primer.

3. Data internal yaitu data yang didapat dari tempat penelitian dengan cara membagikan dan mengumpulkan kembali kuesioner kepada pengunjung Istana Maimun. Dimana data tersebut data mentah dan harus diolehh sebelum diolah menjadi skripsi.

4. Data eksternal adalah data yang didapat dari luar tempat penulisan skripsi seperti internet dan perpustakaan.

\section{Populasi dan Sampel}

Populasi adalah wilayah generaliasi yang terdiri atas objek/subjek yang mempunyai kualitas dan karakteristik tertentu yang ditetapkan oleh peneliti untuk dipelajari dan kemudiann di tarik kesimpulannya (Sugiyono, 2012:115). Penulisan melakukan penelitian populasi penelitian wisatawan khusunya pelajar dan mahasiswa yang dimulai pada bulan April sampai Mei 2017 yaitu 140 orang.

Sampel menurut Sugiyono (2012:116) adalah "bagian dari jumlah dan karakteristik yang dimiliki oleh populasi tersebut". Teknik sampling yang digunakan adalah random sampling. Random sampling adalah teknik pengambilan sampel yang memberikan kesempatan yang sama pada setiapanggota yang ada dalam satu populasi untuk dijadikan sampel. Sampel penelitian yang digunakan adalah teknik slovin dengan rumus

$$
\mathrm{n}=\frac{\mathrm{N}}{1+\mathrm{N}(\mathrm{e})^{2}}
$$


Keterangan

$\mathrm{n}$ : sampel

$\mathrm{N}$ : populasi

e : perkalian tingkat keslaahan

$\mathrm{n}=\frac{140}{1+140(0,05)^{2}=103 \text { orang }}$

Dengan jumlah populasi 140 orang dan perkiraan tingkat kesalahan 5\%. Maka didapat jumlah sampel sebanyak 103 orang.

\section{Metode Pengumpulan Data}

Metode pengumpulan data yang dilakukan dalam penelitian ini sebagai berikut:

1. Studi dokumentasi: pengumpulan data yang dilakukan dengan mencari informasi berdasarkan dokumen-dokumen perusahaan yang berkaitan dengan penelitian

2. Kuesiner: metode pengumpulan data dengan membuat daftar pertanyaan dalam bentuk angket yang ditujukan kepada responden yang dijadikan sampel.

3. Observasi: pengamatan data melalui pengamatan secara langsung di Istana maimun

\section{Defenisi Operasional}

Berdasarkan rumusan masalah, maka variabel-variabel dalam penelitianini dapat diidentifikasi sebagai berikut:

1. Variabel bebas (variabel independen) adalah variabel yang mempengaruhi variabel terikat, yaitu kualitas pelanyanan $(\mathrm{X})$.

2. Variabel terikat (Variable dependen) adalah variabel yang dipengaruhi oleh variabel bebas, yaitu kepuasan wisatawan $(\mathrm{Y})$.

Tabel 1 Operasional Variabel Penelitian

\begin{tabular}{|c|c|c|c|c|}
\hline No & Variabel & Defenisi & Indikator & $\begin{array}{l}\text { Skala } \\
\text { Ukur }\end{array}$ \\
\hline 1 & $\begin{array}{l}\text { Kualitas } \\
\text { Pelayanan }\end{array}$ & $\begin{array}{lcr}\text { Setiap tindakan } & \text { atau } \\
\text { kegiatan yang } & \text { dapat } \\
\text { ditawarkan oleh } & \text { suatu } \\
\text { pihak kepihak lain. } & \end{array}$ & $\begin{array}{ll}\text { 1. } & \text { Reliabilitas } \\
\text { 2. } & \text { Daya tanggap } \\
\text { 3. } & \text { Empati } \\
\text { 4. } & \text { Komunikasi } \\
\text { 5. } & \text { Kesopanan }\end{array}$ & Likert \\
\hline 2 & $\begin{array}{l}\text { Kepuasan } \\
\text { Wisatawa } \\
\mathrm{n}\end{array}$ & $\begin{array}{lr}\text { Kepuasan } & \text { konsumen } \\
\text { merupakan } & \text { tingkat } \\
\text { perasaan seseorang } \\
\text { setelah membandingkan } \\
\text { antara kinerja produk } \\
\text { yang ia rasakan dengan } \\
\text { harapanya. }\end{array}$ & $\begin{array}{l}\text { 1. Kenyamanan dalam museum, seperti } \\
\text { udara bersih, suara tidak berisik. } \\
\text { 2. Pelayanan yang diberikan secara } \\
\text { baik kepada wisatawan. } \\
\text { 3. Kemampuan karyawan dalam } \\
\text { memberikan pelayanan kepada } \\
\text { wisatawan } \\
\text { 4. Perasaan baik yang dirasakan } \\
\text { wisatawan atas pelayanan yang } \\
\text { diberikan oleh Museum Istana } \\
\text { Maimoon. } \\
\text { 5. Sarana dan Prasarana yang } \\
\text { disediakan oleh Istana Maimoon. }\end{array}$ & $\begin{array}{l}\text { Skala } \\
\text { Likert }\end{array}$ \\
\hline
\end{tabular}

Sumber:Kotler dalam Suryadana dan Oktavia(2014:89), Kotler (2012:169), Rusaidi et al (2014:95), Tjiptono (2014:282), Rusaidi et al ( 2014:95)

\section{Uji Validitas dan Reliabitas}

\section{Uji Validitas}

Uji Validitas dilakukan dengan menguji secara statistik butir-butir setiappertanyaan apakah memiliki nilai yang valid atau tidak. Menurut Sugiyono (2012:110) "uji validitas adalah 
suatu langkah pengujian yang dilakukan terhadap isi dari suatu instrumen, dengan tujuan untuk mengukur ketepatan instrumen yang digunakan dalam suatu penelitian". Dikatakan valid jika nilai rhitung $\geq$ rtabel dan dikatakan tidak valid jika nilai rhitung $<$ rtabel.

\section{Uji Reliabilitas}

Menurut Sugiyono (2012:111) “ uji reliabitas adalah proses pengukuranterhadap ketepatan (konsisten) dari instrumen". Dikatakan reliabel jika nilai crombach alfa $>0,6$ dan dikatakan Metode Analisa Data tidak reliabel jika crombach alfa $<0,6$.

Metode analisis data yang digunakan dalam penelitian ini adalah metodedeskriptif kuantitatif, sedangkan model analisis yang digunakan dalam penelitian ini adalah regresi sederhana, dengan model persamaan:

$$
\mathrm{Y}=\mathrm{a}+\mathrm{bX}+\mathrm{e}
$$

Dimana:

$\mathrm{Y}=$ Kepuasan wisatawan

$\mathrm{X}=$ Kualitas Pelayanan

$\mathrm{a}=$ Konstanta

$\mathrm{b}=$ Koefisien regresi variabel kualitas pelayanan

$\mathrm{e}=$ Error of term (variabel yang tidak diteliti)

\section{Kerangka Berpikir}

Sebagaimana yang telah dikemukan sebelumnya bahwa pelayanan sangat erat kaitannya dengan tingkat kunjungan wisatawan. Pelayanan merupakan merupakan kelangsungan hidup dari penghasil produk/jasa, baiknya pelayanan yang diberikan akan tercermin pada aspek kepuasan pelanggan. Kualitas pelayanan adalah hal yang penting dalam suatu produk jasa pelayanan yang baik dapat meningkatkan nilai terhadap jasa yang ditawarkan kepada konsumen. Kepuasan wisatawan yaitu harapan atau persepsi yang berkaitan dengan hal-hal dirasakan konsumen ketika sedang mencoba melakukan transaksi dengan produsen produk.

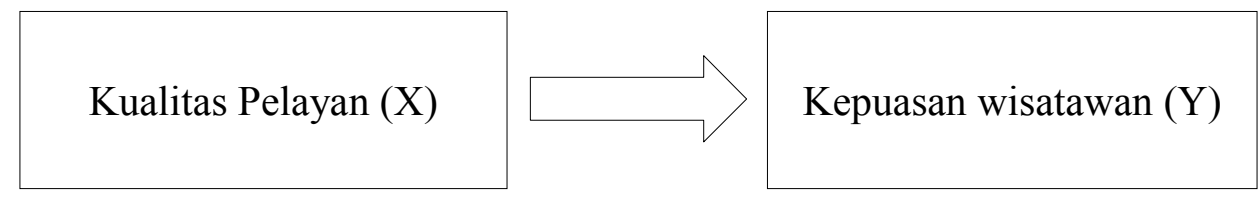

Gambar 1 Kerangka Berpikir

Sumber : Rusiadi et al (2014)

\section{Hipotesis}

Menurut Soewadji (2012:123) hipotesis dapat diartikan sebagai pendapatatau pernyataan atau kesimpulan yang masih kurang atau belum selesai atau masih bersifat sementara. Ia merupakan jawaban yang bersifat sementara terhadap masalah penelitian dimana keberadaannya memerlukan pengujian secara empiris.

Berdasarkan latar belakang masalah dan rumusan masalah yang telah dikemukan dalam penelitian ini adalah:

Ho: Tidak adanya pengaruh yang signifikan kualitas pelayanan terhadap kepuasan wisatwan di Istana Maimoon Medan.

Ho: adanya pengaruh signifikan kualitas pelayanan terhadap kepuasan wisatawan di Istana Maimoon Medan.

Kriteria pengujian hipotesis

Jika thitung $>$ ttabel maka $\mathrm{H}_{1}$ diterima

Jika thitung $<$ ttabel maka $\mathrm{H}_{1}$ ditolak

Maka jawaban sementara untuk penelitian ini adalah adanya pengaruh signifikan antara kualitas pelayanan terhadap kepuasan wisatawan. 


\section{Pengujian Hipotesis}

Pengujian hipotesis adalah suatu prosedur yang dilakukan dengan tujuan memustuskan apakah menerima atau menolak hipotesis mengenai parameter populasi.

a. koefisien determinasi $\left(\mathrm{R}^{2}\right)$

koefisien determinasi $\left(\mathrm{R}_{2}\right)$ pada intinya mengukur seberapa besar kemampuan model dalam merangkan variabel terikat. Semakin besar nilai koefisien determinasi (mendekati satu), maka dapat dikatakan bahwa pengaruh variabel bebas $\left(\mathrm{X}_{1}\right)$ adalah besar terhadap variabel terikat (Y).

b. Uji Parsial (uji t)

Uji parsial (uji t) ini digunakan untuk membuktikan adanya pengaruh yang signifikan antara kualitas pelayanan terhadap kepuasan wisatawan secara parsial, dengan kriteria

1. Jika thitung $\leq$ ttabel maka $\mathrm{H}_{0}$ diterima, $\mathrm{H}_{1}$ ditolak, artinya secara parsial penelitian ini tidak ada pengaruh.

2. Jika thitung $>$ ttabel maka $\mathrm{H}_{0}$ ditolak, $\mathrm{H}_{1}$ diterima, artinya secara parsial penelitian terdapat pengaruh

\section{HASIL DAN PEMBAHASAN}

\section{Uji Validitas dan Reabilitas}

Uji validitas digunakan untuk melihat ketepan instrumen yang digunakan dalam penelitian. Instrument dikatakan valid jika nilai rhitung >rtabel. Hasil validitas dari setiap Instrument variabel adalah sebagai berikut.

Tabel 1 Validitas Instrumen Variabel kualitas pelayanan

\begin{tabular}{|l|l|l|l|}
\hline \multirow{2}{*}{ Instrumen } & \multicolumn{2}{|c|}{ Nilai validitas } & \multirow{2}{*}{ Kesimpulan } \\
\cline { 2 - 3 } & Rhitung & Rtabel & \\
\hline Kualitas Pelayanan 1 & 0,356 & 0,193 & Valid \\
\hline Kulaitas Pelayanan 2 & 0,532 & 0,193 & Valid \\
\hline Kualitas Pelayanan 3 & 0,539 & 0,193 & Valid \\
\hline Kualitas Pelayanan 4 & 0,804 & 0,193 & Valid \\
\hline Kualitas Pelayanan 5 & 0,822 & 0,193 & Valid \\
\hline Kualitas Pelayanan 6 & 0,822 & 0,193 & Valid \\
\hline Kualitas Pelayanan 7 & 0,280 & 0,193 & Valid \\
\hline Kualitas Pelayanan 8 & 0,825 & 0,193 & Valid \\
\hline Kualitas Pelayanan 9 & 0,680 & 0,193 & Valid \\
\hline Kualitas Pelayanan 10 & 0,763 & 0,193 & Valid \\
\hline
\end{tabular}

Dari tabel 1 terlihat bahwa hasil pengujian masing-masing instrument variabel kualitas pelayanan $(\mathrm{x})$ memiliki nilai r-hitung $>0,193$, dengan demikian dapat disimpulkan bahwa secara keseluruhan instrument pernyataan dari variabel kualitas pelayanan yang digunakan valid.

Tabel 2 Validitas instrumen kepuasan Wisatawan

\begin{tabular}{|l|l|l|l|}
\hline \multirow{2}{*}{ Instrumen } & \multicolumn{2}{|l|}{ Nilai Validitas } & \multirow{2}{*}{ Kesimpulan } \\
\cline { 2 - 4 } & & & \\
\hline Kepuasan 1 & 0,266 & 0,193 & Valid \\
\hline Kepuasan 2 & 0,367 & 0,193 & Valid \\
\hline Kepuasan 3 & 0,298 & 0,193 & Valid \\
\hline Kepuasan 4 & 0,312 & 0,193 & Valid \\
\hline Kepuasan 5 & 0,878 & 0,193 & Valid \\
\hline Kepuasan 6 & 0,424 & 0,193 & Valid \\
\hline Kepuasan 7 & 0,879 & 0,193 & Valid \\
\hline Kepuasan 8 & 0,882 & 0,193 & Valid \\
\hline Kepuasan 9 & 0,407 & 0,193 & Valid \\
\hline kepuasan 10 & 0,869 & 0,193 & valid \\
\hline
\end{tabular}


Dari tabel 2 terlihat bahwa hasil pengujian masing masing instrument variabel kepuasan wisatawan (y) memiliki r-hitung $>0,193$, dengan demikian dapat disimpulkan bahwa secara keseluruhan intrumen pernyatan dari variabel kepuasan wisatawan yang digunakan valid.

Uji reabilitas dilakukan untuk menjamin instrumen yang digunakan merupakan instrumen yang handal, konsisten dan stabil jika digunakan secara berulang ulang pada waktu yang berbeda beda. Instrumen dikatakan reliabel jika nilai cronbach's alfa hitung > cronbach'salfa toleransi $(0,6)$. Hasil pengujian reliabel terlihat sebagai berikut.

Tabel 3 Hasil penelitian Instrumen Pelenelitian

\begin{tabular}{|l|l|l|l|}
\hline No & Variabel & $\begin{array}{l}\text { Nilai } \\
\text { Cronbach } \\
\text { Alfa }\end{array}$ & Kesimpulan \\
\hline 1 & Kualitas pelayanan & 0,897 & Reliabel \\
\hline 2 & Kepuasan Wisatawan & 0,856 & Reliabel \\
\hline
\end{tabular}

Hasil uji reabilitas menunjukkan bahwa nilai Cronbach's Alfa seluruh variabel lebih besar dari 0,6, maka dapat disimpulkan hasil penelitian ini reliabel.

\section{Hasil Uji Linier Sederhana}

Pengujian ini dilakukan untuk mengetahui pengaruh kualitas pelayanan terhadap kepuasann wisatawan pada Istana Maimoon. Berikut hasil pengujian regresi linier sederhana sebagai berikut

Tabel 4 Hasil Uji Regresi Linier Sederhana

Coefficients $^{\mathrm{a}}$

\begin{tabular}{|l|l|l|l|l|l|}
\hline \multirow{2}{*}{ Model } & \multicolumn{2}{|l|}{ Unstandardized Coefficients } & $\begin{array}{l}\text { Standardized } \\
\text { Coefficients }\end{array}$ & T & Sig. \\
\cline { 2 - 4 } & $\mathrm{B}$ & Std. Error & Beta & & \\
\hline $\begin{array}{l}\text { (Constant) } \\
\text { kualitas pelayanan }\end{array}$ & 21,080 & 2,845 & & 7,410 &, 000 \\
\hline
\end{tabular}

Berdasarkan hasil pengujian di atas, maka diperoleh persamaan regresi linier sederhana sebagai berikut:

$$
\mathrm{Y}=21,080+0,480+0,75
$$

Pada model regresi sederhana diperoleh nilai konstanta sebesar 21,080 artinya jika nilai variabel bebas nilainya adalah 0 , maka variabel terikat $(\mathrm{Y})$ nilainya sebesar 21,080. Koefiesien regresi masing-masing variabel bebas bernilai positif, ini membuktikan bahwa kepuasan wisatawan dipengaruhi oleh kualitas pelayanan.

\section{Pengujian Hipotesis}

a. koefiesien determinasi $\left(\mathrm{R}^{2}\right)$

koefisien determinasi bertujuan untukk mengukur berapa besar kemampuan variabel bebas dalam menerangkan variabel terikat. Nilai koefisien determinasi dapat dilihat pada tabel berikut:

Tabel 5 Hasil Uji Koefisien Determinasi $\left(\mathrm{R}^{2}\right)$

Model Summary

\begin{tabular}{|l|l|l|l|l|l|l|}
\hline Model & $\mathrm{R}$ & R Square & $\begin{array}{l}\text { Adjusted } \\
\text { Square }\end{array}$ & & & $\begin{array}{l}\text { Std. Error of } \\
\text { the Estimate }\end{array}$
\end{tabular}

Nilai koefisien determinasi yang diperoleh sebesar 0,286 atau 28,6\% menunjukkan bahwa variabel kualitas pelayanan mampu menjelaskan variabel yang terjadi pada kepuasan wisatawan pada Istana Maimoon, sedangkan sisanya 71,4 dijelaskan oleh variabel lain seperti yang tidak diteliti dalam penelitian ini seperti fasilitas Istana Maimoon dan lainnya.

b. Uji Parsial ( uji t)

uji parsial ( uji t) bertujuan untuk melihat pengaruh kualitas pelayanan terhadap kepuasan wisatawan, dengan kriteria: 
1. Jika $\mathrm{r}$ hitung $\leq \mathrm{r}$ tabel maka Ho diterima, $\mathrm{H}_{1}$ di tolak, artinya secara parsial penelitian ini tidak berpengaruh

2. Jika thitung $>t$ tabel maka Ho ditolak, $\mathrm{H}_{1}$ di terima, artinya secara parsial penelitian ini berpengaruh. Tabel 6 Hasil Uji Parsial ( Uji t)

\section{Coefficients $^{\mathrm{a}}$}

\begin{tabular}{|l|l|l|l|l|l|}
\hline \multirow{2}{*}{ Model } & \multicolumn{2}{|l|}{$\begin{array}{l}\text { Unstandardized } \\
\text { Coefficients }\end{array}$} & $\begin{array}{l}\text { Standardized } \\
\text { Coefficients }\end{array}$ & T & \multirow{2}{*}{ Sig. } \\
\cline { 2 - 6 } & $\mathrm{B}$ & Std. Error & Beta & & \\
\hline $\begin{array}{l}\text { (Constant) } \\
\text { kualitas pelayanan }\end{array}$ & $\begin{array}{l}21,080 \\
480\end{array}$ & $\begin{array}{l}2,845 \\
075\end{array}$ &, 535 & $\begin{array}{l}7,410 \\
6,365\end{array}$ &, 000 \\
\hline
\end{tabular}

a.dependent variable: kepuasan wisatawan

Berdasarkan tabel 6 di atas dapat dilihat bahwa: nilai thitung $(6,365)$ lebih besar dibanding ttabel $(1,983)$ dan nilai signikan 0,000 lebih kecil dari alpha 0,05 maka Ho tolak dan $\mathrm{H}_{1}$ diterima, dengan demikan secara parsial variabel kualitas pelayanan berpengaruh berpengaruh positif.

\section{Pembahasan}

Hasil pengujian hipotesis pertama menunjukan bahwa variabel kualitas pelayanan mampu menjelaskan variasi yang terjadi pada kepuasan wisatawan di Istana Maimoon, ini membuktikan ini dibuktikan dengan nilai koefisien determinasi $\left(\mathrm{R}^{2}\right)$ yang diperoleh sebesar 0,286 atau $28,6 \%$, sedangkan sisanya sebesar $71,4 \%$, dijelaskan oleh variabel lain yang tidak di teliti dalam penelitian ini.

Sedangkan hasil pengujian hipotesis yang menggunakan uji t memperlihatkan bahwa variabel kualitas pelayanan berpengaruh terhadap kepuasan wisatawan di Istana Maimoon, ini di buktikan dengan nilai thitung lebih besar dibandingkan dengan nilai ttabel. hasil ini sesuai dengan penelitian sebelumnya yang dilakukan oleh Rosita et al (2016) yang berjudul pengaruh fasilitas wisata dan kualitas pelayanan terhadap kepuasan pengunjung di Taman Marga Satwa Ragunan Jakarta, hasil penelitian menujukkan bahwa secara simultan kualitas pelayanan berpengaruh positif terhadap kepuasan wisatawan.

Penelitain terdahulu menunjukkan terdapat pengaruh kualitas pelayanan terhadap kepuasan wisatawan. dengan demikian sangat jelas bahwa kualitas pelayanan terhadap kepuasan wisatawan di Istana Maimoon. Oleh sebab itu seharusnya manajemen Istana Maimoon lebih meningkatkan kualitas pelayanan, diantaranya dengan lebih memperhatikan wisatawan seperti meningkatkan inisiatif pramuwisata memberikan informasi kepada wisatawan.

\section{KESIMPULAN}

Berdasarkan penelitian dan pembahasan pada bab sebelumnya, maka pada bab terakhir diperoleh kesimpulan secara parsial variabel kualitas pelayanan berpengaruh postitf terhadap kepuasan wisatawan pada Istana Maimoon Medan dengan nilai 28.6\%. Dimana pelayanan suatu merupakan tolak ukur dari kepuasan pelanggan atau wisatawan. Dengan memberikan pelayanan yang baik sesuai dengan standart perusahaan maka wisatawan akan merasa puas akan pelayanan yang ada. 


\section{REFERENCES}

Adya, B. A. (2013). Pelayanan Prima (1st ed.). Jakarta: Gramedia.

Alditia, D., Sofia, A., \& Ari, A. K. (2014). Pengaruh Kualitas Pelayanan Terhadap Kepuasan Pegunjung Di Objek Wisata Riau Fantasi Labersa Water \& Themepark. Mahasiswa Kampus Bina Widya, 15, 1.

Daryanto, \& Ismanto, S. (2014). Konsumen dan Pelayanan Prima (1st ed.). Yogjakarta: Gava Media.

Fandy, T. (2014). Pemasaran Jasa (1st ed.). Yogjakarta: Andi Offset.

Handi, D. I. (2011). Pemasaran Jasa. Jakarta: Grasindo.

Liga, S. M., \& Vanny, O. (2015). Pengantar Pemasaran Pariwisata (1st ed.). Bandung: Alfabeta.

Philip, K., \& Lane, keller K. (2012). Marketing manajement (14th ed.). New Jersey: Pearson Edition.

Rosita, Sri, M., \& Hanoum, H. W. (2016). Pengaruh Fasilitas Wisata dan Kualitas Pelayanan Terhadap Kepuasan Pengunjung Di Taman Margasatwa Ragunan Jakarta. Universitas Pendidilkan Indonesia, 72, 1.

Rusaidi. (2014). Metode penelitian. Medan: Usu Press.

Sudaryono. (2016). Manajemen Pemasaran Teori Implentasi (1st ed.). Yogjakarta: Andi Offset.

Sugiyono. (2012). Metode Penelitian Bisnis ( Pedekatan Kuantitaf, Kualitatif dan R\&D). Bandung: Alfabeta.

Winata, E. (2016). Pengaruh Kepuasan Kerja dan Kompensasi terhadap Kinerja Karyawan pada Hotel Inna Dharma Deli Medan. Jurnal Ilman, 4(1), 1-17.

Winata, E. (2016). PENGARUH KOMPENSASI DAN KOMUNIKASI TERHADAP SEMANGAT KERJA KARYAWAN PADA PT. FIF CABANG MEDAN. Jurnal Dunia Ilmu, 2(1), 17-31.

Winata, E. (2017). PENGARUH BAURAN PEMASARAN JASA TERHADAP LOYALITAS KONSUMEN PADA GRAND SERELA HOTEL \& CONVENTION MEDAN. Jurnal Mutiara Manajemen, 1(1), 109-121. 